\title{
Nanoscale Ion Dynamics Control on Amorphous Calcium Carbonate Crystallization: Precise Control of Calcite Crystal Sizes
}

\author{
Maria P. Asta,* Alejandro Fernandez-Martinez, Juan Alonso, Laurent Charlet, Nathaniel Findling, \\ Valerie Magnin, Beatrice Ruta, Michael Sprung, and Fabian Westermeier
}

Cite This: J. Phys. Chem. C 2020, 124, 25645-25656

Read Online

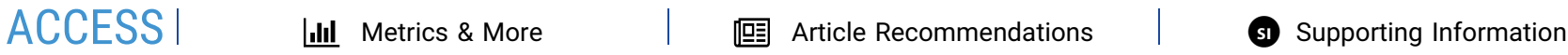

ABSTRACT: Amorphous calcium carbonate (ACC) is an essential component present during the early stages of biomineralization of many calcifying organisms, which is used as a precursor of crystalline calcium carbonate phases. Here, we performed X-ray photon correlation spectroscopy experiments on ACC which show that the amount of adsorbed water has a strong control over its diffusive dynamics. Results of crystallization experiments under conditions of controlled humidity indicate that the adsorbed water is enough to spark crystallization of calcite. A direct proportionality is found between the relative humidity of the environment and the final size of the calcite crystals. Different hypotheses are made to explain this result, with the confinement within the amorphous

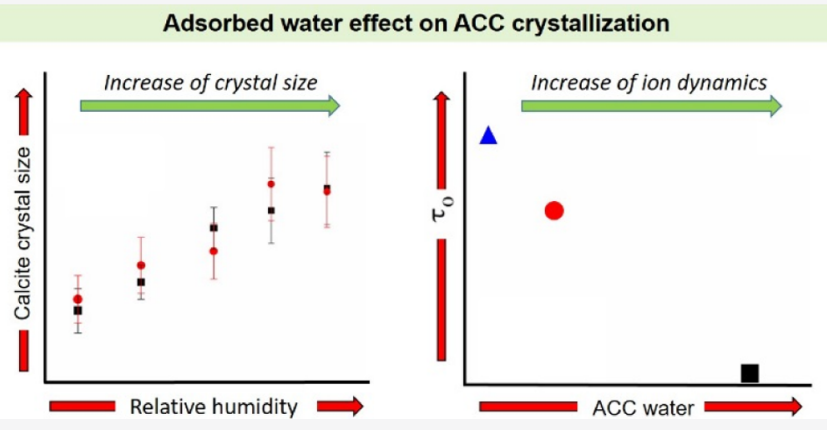
matrix being the main suspect of controlling the size of the crystallites. Control of water activity and water content is, therefore, a possible way to regulate biomineral crystallinity both in nature and for the design of functional biomimetic materials.

\section{INTRODUCTION}

Amorphous calcium carbonate (ACC) is found in the early stages of biomineral formation, ${ }^{1}$ where it acts as a precursor for the main calcium carbonate polymorphs, aragonite, ${ }^{2}$ and calcite. ${ }^{3}$ The amorphous precursor strategy allows controlling the kinetics of biomineral crystallization and the spatial distribution of the final crystalline polymorphs. ${ }^{4}$ Both aragonite and calcite biominerals are present in nature, with intricate shapes such as those of the aragonite tablets forming nacre ${ }^{2}$ or the complex mesostructure of sea urchin spicules. ${ }^{3}$ This exquisite control of the micro and mesostructure gives biominerals extraordinary mechanical properties, such as strength, hardness, or resistance to flexion. However, and in spite of recent advances in the field, ${ }^{5,6}$ the molecular-scale mechanisms controlling the crystallization kinetics remain largely unknown.

A large number of studies have been devoted in the recent years to improve our understanding of the crystallization mechanisms and kinetics of the transient amorphous precursor to crystalline carbonates. However, in spite of the low water chemical potential present in the membrane-bound vesicular compartments where $\mathrm{CaCO}_{3}$ biominerals are formed (e.g., sea urchin, ${ }^{7}$ molluscan shells, ${ }^{8}$ or cyanobacteria, ${ }^{9}$ among others ${ }^{10}$ ), only few studies have reported ACC crystallization data under these conditions. ${ }^{11-13}$ Both dissolution/recrystallization and solid-state transformations have been considered as possible mechanisms acting in the transformation of ACC to vaterite, calcite, and aragonite. ${ }^{11,12,14,15}$ Ihli et al. ${ }^{12}$ studied ACC crystallization under dry conditions and reported values for the activation energies $\left(E_{\mathrm{a}}\right)$ of the ACC-to-crystalline $\mathrm{CaCO}_{3}$ transition that are directly proportional to the level of ACC hydration. These authors reported $E_{\mathrm{a}}$ values ranging from $\sim 125$ to $250 \mathrm{~kJ} / \mathrm{mol}$ for ACC samples containing relatively low water contents $\left(\sim 0.6\right.$ to $0.2 \mathrm{~mol}$ of $\mathrm{H}_{2} \mathrm{O}$ per $\left.\mathrm{CaCO}_{3}\right)$, suggesting that crystallization proceeds via a solid-state transition. On the contrary, other studies showed that humidity favors the dissolution/recrystallization pathway, ${ }^{11,13}$ and the transformation of ACC into crystalline $\mathrm{CaCO}_{3}$ occurs only after the physisorption of water. ${ }^{13}$

The structure of ACC is highly hydrated, with an average number of $1-1.5 \mathrm{~mol} \mathrm{H}_{2} \mathrm{O} / \mathrm{mol} \mathrm{CaCO}_{3}$. Due to its water content, together with its "space-filling" character ${ }^{4}$ and its low compressibility, ${ }^{16}$ it can be considered a "soft" material. Water acts as a mediator of crystallization processes in soft matter via the activation of dynamic modes and diffusion pathways that enhance the dynamics within the material and helps overcoming crystallization barriers. ${ }^{17,18}$ Whether these processes take place via a dissolution-precipitation or a solid-state pathway may be a question of wording in some cases; the

Received: September 23, 2020

Revised: October 19, 2020

Published: November 4, 2020

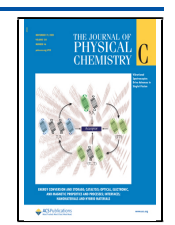


presence of adsorbed water in ACC pores may lead to capillary condensation and thus to the occurrence of bulk-like water environments within the 'solid' powder particles of ACC, in such a way that dissolution-reprecipitation processes take place within the layers of adsorbed water, where diffusion is activated by this type of water. A characterization of the different water and ionic environments, both from the structural and dynamical point of view, is therefore needed to ascertain the precise mechanisms underlying crystallization processes.

Different structural environments for water in ACC have been reported that can be classified mainly as adsorbed and structural molecular water and as hydroxyl groups in more basic and $\mathrm{Mg}^{2+}$-bearing ACC. ${ }^{19-24}$ Water in ACC has also been shown to be at least partially responsible for the kinetic persistence of its amorphous structure, via the formation of a hydrogen bond network of water molecules and carbonate ions. ${ }^{25}$ The diffusive dynamics of both the hydrous and ionic components of ACC have been studied using X-ray and neutron scattering techniques showing a highly dynamic environment compared with, for example, covalent or metal glasses. $^{23,26-28}$ The nanoscale dynamics have been related to the crystallization kinetics of ACC, showing how the presence of foreign ions can affect water dynamics, enhancing its kinetic persistence. $^{26} \mathrm{X}$-ray photon-correlation studies of ACC and $\mathrm{Mg}^{2+}$-doped ACC have shown that there is a direct proportionality between the $\mathrm{Mg}^{2+}$ concentration and the frequency of structural rearrangements undergone by structural entities within the amorphous material. ${ }^{26}$ This frequency may be directly interpreted as the frequency of collision within the kinetic term of classical nucleation theory, allowing a quantitative interpretation of the link between molecular dynamics and the crystallization rate. ${ }^{26,29}$ In the previous studies, a key question remained unanswered regarding the activation of the dynamics in the presence of $\mathrm{Mg}^{2+}$. The study by Koishi et al. ${ }^{26}$ shows that the inclusion of $\mathrm{Mg}^{2+}$ in the ACC structure enhances the internal dynamics, but it also results in a more hydrated environment. A link with the internal dynamics is therefore not unambiguous because two factors (the presence of $\mathrm{Mg}^{2+}$ and the presence of water) could be responsible for the enhanced dynamic character of the solid. In addition, it has been recently shown that $\mathrm{Mg}^{2+}$ ions have a distinct coordination environment compared to $\mathrm{Ca}^{2+}$ in ACC. ${ }^{30}$

Here, we propose a way around this question by performing the same kind of experiments on pure ACC samples but with different degrees of hydration. In addition, we characterize the crystallization kinetics and microstructure of the final calcite. $\mathrm{X}$-ray photon correlation spectroscopy (XPCS) experiments reveal a direct proportionality between the amount of water in the ACC structure and its internal dynamics, showing an unexpected reversible behavior of the dynamics upon dehydration and rehydration cycles. The results of ACC crystallization experiments under controlled relative humidity (RH) show that the size of the calcite crystals depends on humidity. Different hypotheses are made and discussed to explain this fact. Limited ionic diffusivity within the solids is proposed to be mainly responsible for the nanoscale, controlled final size of the calcite crystals obtained at the end of the experiments.

\section{METHODS}

Sample Preparation. The synthesis procedure of ACC consists of an equivolume mixture of fresh solutions of $0.02 \mathrm{M}$ $\mathrm{CaCl}_{2}$ and $0.02 \mathrm{M} \mathrm{Na}_{2} \mathrm{CO}_{3}+0.2 \mathrm{M} \mathrm{NaOH}$ at $4{ }^{\circ} \mathrm{C}$ followed by immediate (seconds) quenching with dry acetone and vacuum filtration. ${ }^{31}$ The mixture typically yields a $\mathrm{pH} \sim 13$, which favors the precipitation of amorphous basic calcium carbonate of long-term stability. ${ }^{26}$ Before the synthesis, all glassware was cleaned with $20 \% \mathrm{HCl}$ to remove any possible nucleation loci and rinsed thoroughly with ultrapure water. Glassware, as well as all the solutions used in the synthesis, was kept in a $4{ }^{\circ} \mathrm{C}$ refrigerator before use. After synthesis, ACC samples were kept in a dry desiccator until confirmation of their non-crystalline nature by powder X-ray diffraction (XRD) and attenuated total reflectance Fourier transform infrared spectroscopy (ATR-FTIR).

Analysis Techniques. ATR-FTIR spectra of the ACC samples were obtained using a Thermo Fisher Scientific Nicolet iS550 FTIR equipped with a single reflection ATR diamond crystal, in the $525-4000 \mathrm{~cm}^{-1}$ range with a $4 \mathrm{~cm}^{-1}$ resolution. A total of 64 scans were averaged for each sample and background.

The mineralogical composition was determined by XRD using a Bruker D8 DISCOVER diffractometer with $\mathrm{Cu} \mathrm{K} \alpha$ radiation (wavelength $=1.54 \AA$ ). Data were recorded in a continuous-scan mode in the $20-60^{\circ} 2 \theta$ range with a step of $0.026^{\circ}$. XRD patterns of fresh samples were measured within $30 \mathrm{~min}$ after drying, and in all cases, no crystalline peaks were observed.

Thermogravimetric analysis (TGA) and differential scanning calorimetry analyses were performed using a Mettler Toledo TGA/DSC3+. Around $5 \mathrm{mg}$ of dry powdered sample was placed in an alumina crucible, and the sample was heated from 25 to $750{ }^{\circ} \mathrm{C}$ under a $20 \mathrm{~mL} / \mathrm{min} \mathrm{N}_{2}$ flow. The temperature scanning rate was set to $20{ }^{\circ} \mathrm{C}$ per min.

XPCS analysis of three samples with different water contents (see below for sample preparation) was carried out at the P10 beamline of the synchrotron radiation source PETRA II (DESY, Germany). The samples were prepared by loading the powders into $1 \mathrm{~mm}$ diameter holes drilled in $\sim 100 \mu \mathrm{m}$ thick $\mathrm{Al}$ foils. This thickness ensures $\sim 9 \%$ of transmission at $15 \mathrm{keV}$ (energy of incident radiation). Measurements were performed under an active vacuum (of $\sim 10^{-3} \mathrm{mbar}$ ), at $T=25^{\circ} \mathrm{C}$, covering a $\mathrm{q}$ range of $0.0037-0.023 \AA^{-1}$ (small-angle X-ray scattering configuration), and with a beam size of $15 \times 15 \mu \mathrm{m}$. Series of speckles patterns were collected in transmission geometry using a CCD detector (Andor, $13 \mu \mathrm{m}$ pixel size). A delay time (waiting time between two consecutive frames) of $1.9 \mathrm{~s}$ was set after each $0.1 \mathrm{~s}$ acquisition in order to prevent radiation damage of the samples. Intensity autocorrelation functions obtained at different $\mathrm{q}$ values were fitted using the Kohlrausch-Williams-Watts model

$$
g^{(2)}(t)=1+c \times \exp \left(-2(t / \tau)^{\beta}\right)
$$

where $c$ is the setup-dependent contrast, $\tau$ is the structural "relaxation time", which is the characteristic period of time for the system to attain a spatial arrangement different from that of a given initial time point, and $\beta$ is a "shape factor" referring to the nature of the relaxation process. Values of $\beta=1$ are expected for ideal Brownian diffusion, and values of $\beta>1$ suggest a deviation from the ideal diffusive behavior. ${ }^{32}$ 
Samples analyzed by XPCS were synthesized with the method described above. One sample (ACC) was measured as synthesized, and two others (ACC- $140{ }^{\circ} \mathrm{C}$ and ACC-250 ${ }^{\circ} \mathrm{C}$ ) were subjected to thermal treatments up to 140 and $250{ }^{\circ} \mathrm{C}$ using a TGA instrument (NETZSCH TGA 209 F1 Iris, Univ. Hamburg) just prior to the XPCS experiments. The loss of water due to active vacuum pumping during XPCS experiments was tested by ex situ TGA measurements after subjecting the samples to the same level of vacuum as in the XPCS sample chamber.

RH-Controlled Experiments. Crystallization experiments were performed under conditions of controlled humidity. Once ACC is formed, filtered, and verified to be amorphous by ATR-FTIR and XRD, samples were transferred to desiccators containing saturated-salt solutions (potassium acetate, magnesium chloride, potassium carbonate, magnesium nitrate, sodium chloride, potassium chloride, and potassium nitrate (to get $23,33,45,60,75,85$, and $90 \%$ of $\mathrm{RH}$, respectively). ${ }^{33-35}$ The $\mathrm{RH}$ was monitored during the experiments with digital hygrometers with an accuracy of $\pm 5 \%$. At different experimental times, the solid was quickly sampled, and no important variations in the $\mathrm{RH}$ were observed due to the sampling. These sampled solids were analyzed by ATR-FTIR, TGA-differential scanning calorimetry (DSC), and XRD at different reaction times.

\section{RESULTS}

Ion Dynamics as a Function of the Initial Degree of Hydration. XPCS intensity autocorrelation curves of the three samples (ACC, ACC- $140{ }^{\circ} \mathrm{C}$, and ACC- $250{ }^{\circ} \mathrm{C}$ ) obtained at $q$ $=0.016 \AA^{-1}$ are shown in Figure 1a. The initial relaxation times, $\tau_{0}$, and the initial values of the shape factor, $\beta_{0}$, are shown in Figure 2a,b, respectively, (see also Table S1 for values of the frequency of structural rearrangements). The results show shorter relaxation times for more hydrated samples, that is, faster dynamics. The shape exponent of the as-synthesized ACC sample has a value $\beta_{0}=1.1 \pm 0.1$, compatible with the ideal value of 1 expected for ideal Brownian diffusion. This value increases for samples treated at $140{ }^{\circ} \mathrm{C}$ and $250{ }^{\circ} \mathrm{C}\left(\beta_{0}>1.0\right)$, suggesting a deviation from ideal diffusive behavior (Figure 2b, Table S1).

Time Evolution of the Dynamics. Ex situ TGA experiments show that the active vacuum during the XPCS experiments results in water release from the samples (Figure $3)$. The evolution of the relaxation time $(\tau)$ with experimental time (obtained at $q=0.016 \AA^{-1}$ ) is shown in Figure 4. An increase of $\tau$ with time is observed for all four samples, indicating a slowing down of the relaxation dynamics or aging. The slope of the $\tau$ versus $t$ curves show similar values for samples ACC (Figure 4a) and ACC-250 ${ }^{\circ} \mathrm{C}$ (Figure 4e), significantly lower than those of sample ACC-140 ${ }^{\circ} \mathrm{C}$ (Figure 4c) where two specimens have been measured. Relaxation times for ACC seem to reach a plateau after $\sim 200 \mathrm{~min}$, with values of $\tau \sim 1,500 \mathrm{~s}$ (Figure 4a). Samples with lower water content show longer relaxation times after aging, with no sign of stabilization (Figure 4c,e). The evolution of the shape factor for ACC is shown in Figure 4b, showing an evolution from an initial value close to 1 (ideal Brownian diffusion) followed by a significant increase up to values close to $\beta \sim 2$. Values of the shape factor for dehydrated samples are higher from the beginning, with values always around $\beta \sim 2$ (Figure 4d,f).

Reversible Ion Dynamics. To evaluate the reversibility of the ion dynamics, ACC and ACC-250 ${ }^{\circ} \mathrm{C}$ samples were
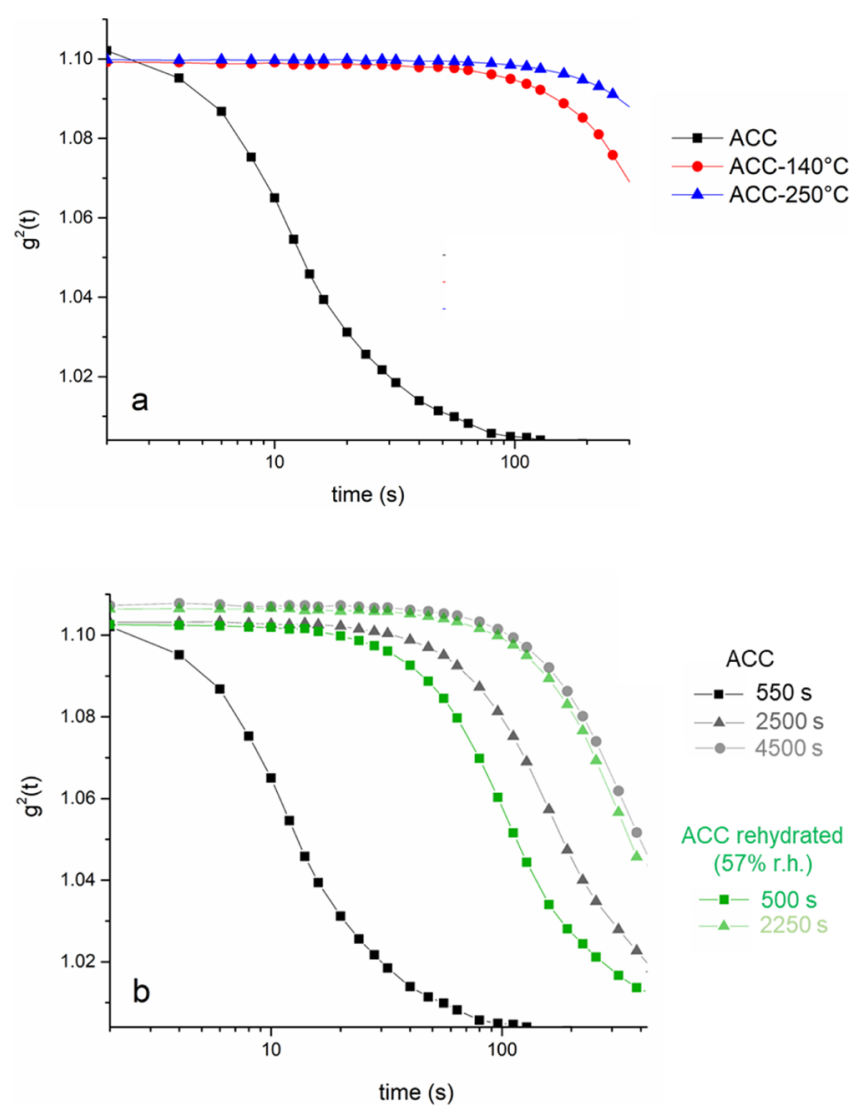

Figure 1. Time-evolution of the intensity autocorrelation functions at $q=0.016 \AA^{-1}$ obtained from the XPCS measurements for the ACC sample (fresh sample) and two ACC samples treated up to 140 and $250{ }^{\circ} \mathrm{C}$ at $1540 \mathrm{~s}$ after the start of the XPCS measurements (a) and for the same fresh ACC sample and after exposure to $57 \%$ of relative humidity for $270 \mathrm{~min}$ (b). Time (s) in (b) are the elapsed times after the start or re-start of the XPCS measurements.

exposed to humidity over a given period of time (see Table S2). The ACC sample was recovered after the XPCS experiment $(t \sim 515 \mathrm{~min})$ and exposed to $35 \% \mathrm{RH}$ for 20 $\min$ and to $57 \%$ of $\mathrm{RH}$ for $270 \mathrm{~min}$ (see intensity autocorrelation curves in Figure $1 \mathrm{~b}$ ). Subsequent XPCS experiments showed that exposure to $35 \% \mathrm{RH}$ did not have a strong effect on the relaxation time, nor on the $\beta$ parameter, which followed the same trends of ACC as before the exposure to humidity (Figure 4a,b). However, after being exposed to $57 \% \mathrm{RH}$, both $\tau$ and $\beta$ values decreased significantly, indicating a reactivation of the relaxation dynamics. The decrease of the values of $\beta$ from $\sim 2$ to $\sim 1.55$ after re-hydration indicates a change in the nature of the dynamics, closer to ideal Brownian behavior. The results suggest that ion diffusion in ACC is a reversible process upon sample rehydration.

Ex situ TGA measurements performed on ACC samples subject to the same vacuum conditions and after $180 \mathrm{~min}$ of exposure to $55 \%$ of $\mathrm{RH}$ show the reversibility of the hydration process in agreement with the XPCS results. The ACC sample had an initial $1.36 \mathrm{~mol}$ of water per mole of $\mathrm{CaCO}_{3}\left(\mathrm{CaCO}_{3}\right.$. $1.36 \mathrm{H}_{2} \mathrm{O}$ ). About $0.38 \mathrm{~mol}$ of water was lost during the first vacuum cycle (ACC composition of $\mathrm{CaCO}_{3} \cdot 0.98 \mathrm{H}_{2} \mathrm{O}$ ). After exposure to humidity, an increase of $0.03 \mathrm{~mol}$ of water was observed $\left(\mathrm{CaCO}_{3} \cdot 1.01 \mathrm{H}_{2} \mathrm{O}\right.$, Figure 3). After rehydration, the sample was subjected to a new vacuum cycle of $100 \mathrm{~min}$ causing a loss of $0.1 \mathrm{~mol}$ of water $\left(\mathrm{CaCO}_{3} \cdot 0.91 \mathrm{H}_{2} \mathrm{O}\right)$. The 

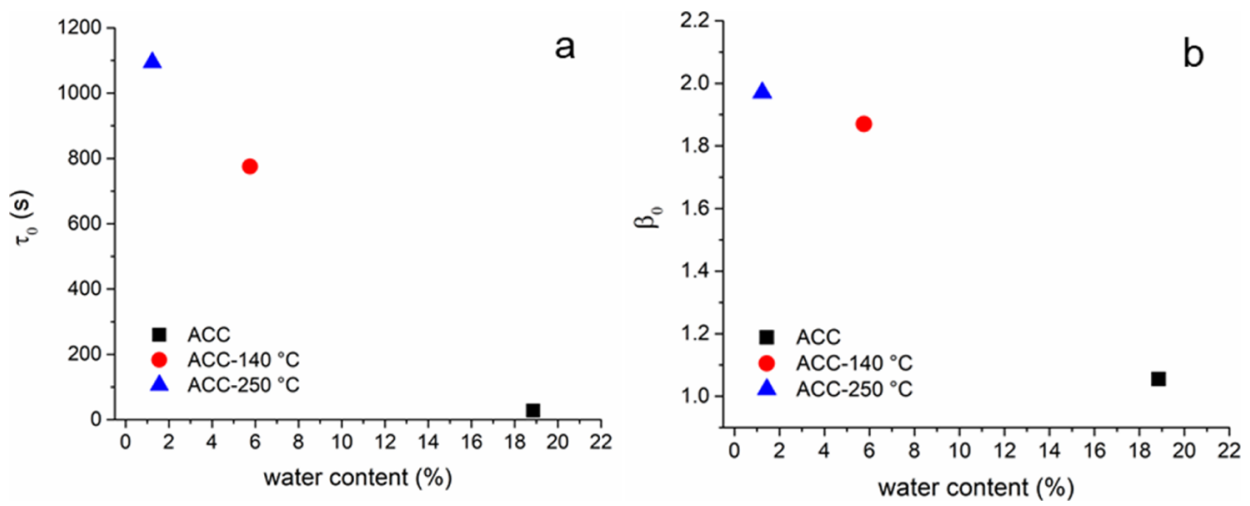

Figure 2. (a) Initial relaxation times $\left(\tau_{0}\right)$ and (b) initial shape exponents $\left(\beta_{0}\right)$ as a function of water content for an ACC sample (thermally untreated) and two ACC samples treated up to 140 and $250{ }^{\circ} \mathrm{C}$. The water content (\%) in each sample was quantified from the weight loss in the TGA.
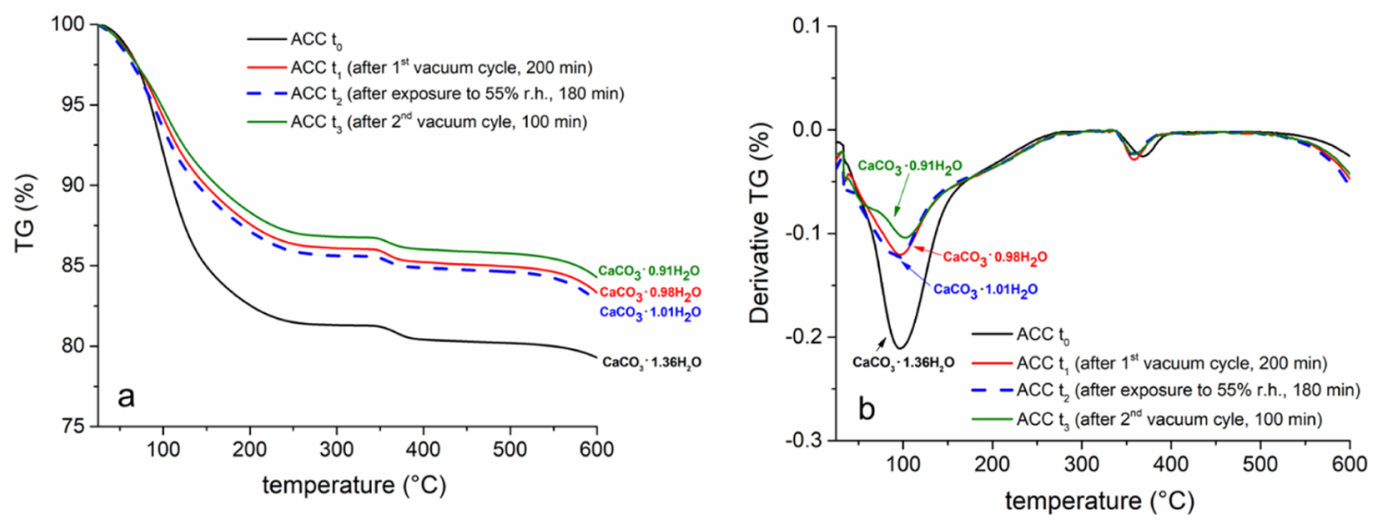

Figure 3. Thermal analyses of a fresh ACC sample $\left(t_{0}\right)$ exposed in consecutive steps to vacuum $\left(t_{1}\right), 55 \%$ RH $\left(t_{2}\right)$, and vacuum $\left(t_{3}\right)$. (a) TGA curves and (b) their first derivatives of the ex situ measurements performed on ACC (ACC $t_{0}$, black line) and ACC after being subjected to two vacuum cycles of $200 \mathrm{~min}$ (ACC $t_{1}$, red line) and $100 \mathrm{~min}$ (ACC $t_{3}$, green line) and after exposure to $55 \%$ relative humidity for $180 \mathrm{~min}$ (ACC $t_{2}$, dashed blue line).

TGA and the derivative of the TGA values indicate a mass loss and rehydration in the range of $50-150{ }^{\circ} \mathrm{C}$, commonly identified as adsorbed water or weakly bound water. ${ }^{11}$ The same kind of experiments performed with the ACC-250 ${ }^{\circ} \mathrm{C}$ sample shows an initial, very slight reactivation of the dynamics but followed in this case by an abrupt slowing down of the sample system (Figure 4e). A close analysis of the two-time correlation function (Figure S1) reveals the presence of a sudden event. We hypothesize that this is due to an abrupt change in the microscopic dynamics of the sample (avalanche, partial crystallization). ${ }^{36}$ Another hypothesis would involve a possible instrumental effect (sample movement), though we consider it to be less likely, given the high stability of the beam and sample positions observed throughout the experiment.

ACC Crystallization Experiments. A convenient way to perform crystallization experiments under controlled water activity conditions is the use of a controlled atmosphere at a given $\mathrm{RH}$. Even though this approach lacks the complexity of the real vesicle system characteristic of some organisms, where confinement is susceptible to play a role in ACC crystallization kinetics, ${ }^{10,37}$ it allows studying the specific effect of water content on the crystallization products. Experiments were performed by placing freshly synthesized ACC samples in desiccators with controlled humidity values of $23,33,45,60$, 75,85 , and $95 \%$. The non-crystalline nature of the assynthesized samples was confirmed by ATR-FTIR and XRD (Figures S2 and S3). Samples were collected at different times after exposure, and their crystallinity was characterized with XRD and ATR-FTIR, and their water content was evaluated using TGA-DSC. The DSC analysis of fresh ACC is shown in Figure S4, illustrating the typical features of ACC as described in previous works. ${ }^{13,19}$ TGA analysis showed that the initial ACC precipitate contained 1.19-1.49 mol of water, which is gradually lost during ACC crystallization after exposure to different RH (Table 1). The kinetics of the dehydration process increase as $\mathrm{RH}$ increases (Figure 5). As previously described, dehydration is accompanied by a structural rearrangement in ACC; the water absorption bands at $2600-3700$ and $1645 \mathrm{~cm}^{-1}$ corresponding to water stretching and bending disappear and the carbonate bending absorption at around $862 \mathrm{~cm}^{-1}$ is shifted to $876 \mathrm{~cm}^{-1}$, indicative of carbonate crystallization (Figures S2 and 6). ${ }^{12}$ Under low RH (up to 33\%), the FTIR spectra do not show changes indicative of transformation and crystallization for 43 days. In contrast, for ACC exposed to medium RH $(45,60$, and $75 \%)$, the water absorption band decreased and the $\nu_{2}$ absorption band of the carbonate started to shift after 1, 3, and 16 days, respectively. At the highest RH ( 85 and 95\%), the water absorption bands disappeared after one day and the $\nu_{2}$ absorption band of the carbonate shifted to $876 \mathrm{~cm}^{-1}$, indicating the ACC transformation to crystalline phases (Figure 6). After 43 days, no sign of crystallization is observed neither in the ACC placed at $23 \% \mathrm{RH}$ nor at $33 \%$. The diffraction patterns showed calcite and vaterite peaks after one day of exposure of ACC to the 

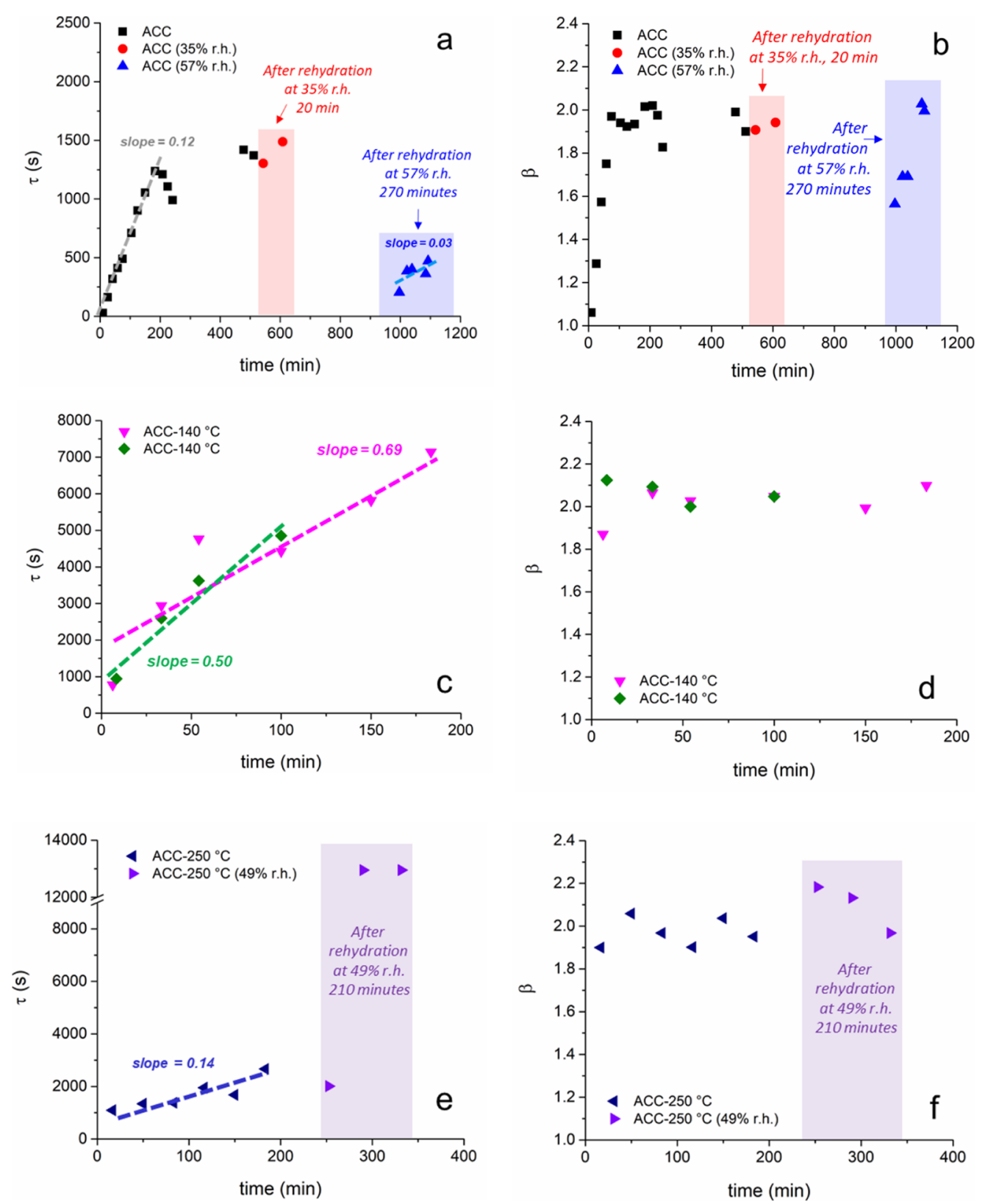

Figure 4. Relaxation times $(\tau)$ [panels (a,c,e)] and shape exponent $\beta$ [panels $(\mathrm{b}, \mathrm{d}, \mathrm{f})]$ as a function of the experimental time for ACC and ACC samples treated up to 140 and $250{ }^{\circ} \mathrm{C}$. Dashed lines are linear fits to the data, which show an increase in the slope in the dehydrated samples. Shadowed areas correspond to the measurements performed after sample exposure to different levels and time intervals of relative humidity.

highest RH values (Figure 7), which agrees with the FTIR results and with past observations of accelerated crystallization kinetics under high $\mathrm{RH}^{11}$ Overall, XRD, TGA, and FTIR results indicate that the amount of water in the environment affects the time required to start the crystallization and the time needed for its completion.

Crystalline domain sizes were obtained from the most intense diffraction calcite peak at $29.4^{\circ}$ by the X-ray line broadening method using the Scherrer equation. ${ }^{38}$ The coherent domain size is found to evolve with time at a rate directly proportional to the $\mathrm{RH}$ value (Figure 8 ). Interestingly, after 16-18 days, a maximum size is reached with values in the nanoscale, and a direct proportionality between the final crystallite size and the RH is observed (Figure 9), with the values stabilizing at $\sim 120 \mathrm{~nm}$ for the two samples subject to highest humidity.

\section{DISCUSSION}

Water Content and Type in ACC Control Ion Dynamics. Initial values of the relaxation times obtained from XPCS experiments (when the samples are less affected by the active vacuum during XPCS experiments) confirm the expected trend of diffusivity proportional to the water content within the samples. The high values found for the shape exponent of partially dehydrated samples (ACC- $140{ }^{\circ} \mathrm{C}$ and ACC-250 ${ }^{\circ} \mathrm{C}$ ), with $\beta_{0} \sim 2$, is consistent with studies showing dynamic behavior that deviates from Brownian diffusion and is related to internal stresses of the materials. ${ }^{26,39,40}$ The active vacuum during the experiment induces a partial dehydration that, although minor, is enough to trigger small structural changes [not detected during XPCS experiments, see scattering intensity $I(q)$ in Figure S5], ${ }^{26,27}$ which are accompanied by an increase in the stress within the hydrated 
Table 1. Water Content and Crystallinity of Synthesized ACC Over Time under Different Relative Humidity Conditions Obtained by Thermogravimetric and XRD Measurements

\begin{tabular}{|c|c|c|c|c|c|c|c|c|c|}
\hline $\mathrm{RH}(\%)$ & days & water (wt \%) & $\mathrm{CaCO}_{3} \cdot x \mathrm{H}_{2} \mathrm{O}$ & crystallinity & $\mathrm{RH}(\%)$ & days & water (wt \%) & $\mathrm{CaCO}_{3} \cdot x \mathrm{H}_{2} \mathrm{O}$ & crystallinity \\
\hline \multirow[t]{6}{*}{23} & 0 & 19.7 & 1.35 & amorphous & 75 & 0 & 20.4 & 1.42 & amorphous \\
\hline & 1 & 19.0 & 1.30 & amorphous & & 1 & 18.6 & 1.24 & amorphous + crystalline \\
\hline & 2 & 18.8 & 1.29 & amorphous & & 2 & 16.6 & 1.08 & amorphous + crystalline \\
\hline & 3 & 18.6 & 1.27 & amorphous & & 3 & 13.3 & 0.84 & amorphous + crystalline \\
\hline & 16 & 17.3 & 1.16 & amorphous & & 24 & & & crystalline \\
\hline & 43 & 16.7 & 1.11 & amorphous & & 43 & & & crystalline \\
\hline \multirow[t]{6}{*}{33} & 0 & 21.2 & 1.49 & amorphous & 85 & 0 & 19.8 & 1.37 & amorphous \\
\hline & 1 & 20.3 & 1.41 & amorphous & & 1 & & & crystalline \\
\hline & 2 & 19.4 & 1.33 & amorphous & & 2 & & & crystalline \\
\hline & 3 & 19.4 & 1.34 & amorphous & & 3 & & & crystalline \\
\hline & 16 & 19.5 & 1.35 & amorphous & & 22 & & & crystalline \\
\hline & 43 & 20.2 & 1.41 & amorphous & & 48 & & & crystalline \\
\hline \multirow[t]{6}{*}{45} & 0 & 17.6 & 1.19 & amorphous & 95 & 0 & 20.4 & 1.43 & amorphous \\
\hline & 1 & 17.7 & 1.20 & amorphous & & 1 & & & crystalline \\
\hline & 2 & 17.9 & 1.21 & amorphous & & 2 & & & crystalline \\
\hline & 3 & 18.8 & 1.29 & amorphous & & 3 & & & crystalline \\
\hline & 16 & 16.0 & 1.06 & amorphous + crystalline & & 16 & & & crystalline \\
\hline & 43 & 14.4 & 0.94 & crystalline & & 48 & & & crystalline \\
\hline \multirow[t]{6}{*}{60} & 0 & 19.2 & 1.32 & amorphous & 95 & 0 & 20.4 & 1.44 & amorphous \\
\hline & 1 & 19.0 & 1.30 & amorphous + crystalline & & 1 & & & crystalline \\
\hline & 2 & 18.7 & 1.28 & amorphous + crystalline & & 2 & & & crystalline \\
\hline & 3 & 15.1 & 0.99 & amorphous + crystalline & & 3 & & & crystalline \\
\hline & 16 & 3.9 & 0.23 & crystalline & & 16 & & & crystalline \\
\hline & 43 & & & crystalline & & 43 & & & crystalline \\
\hline
\end{tabular}
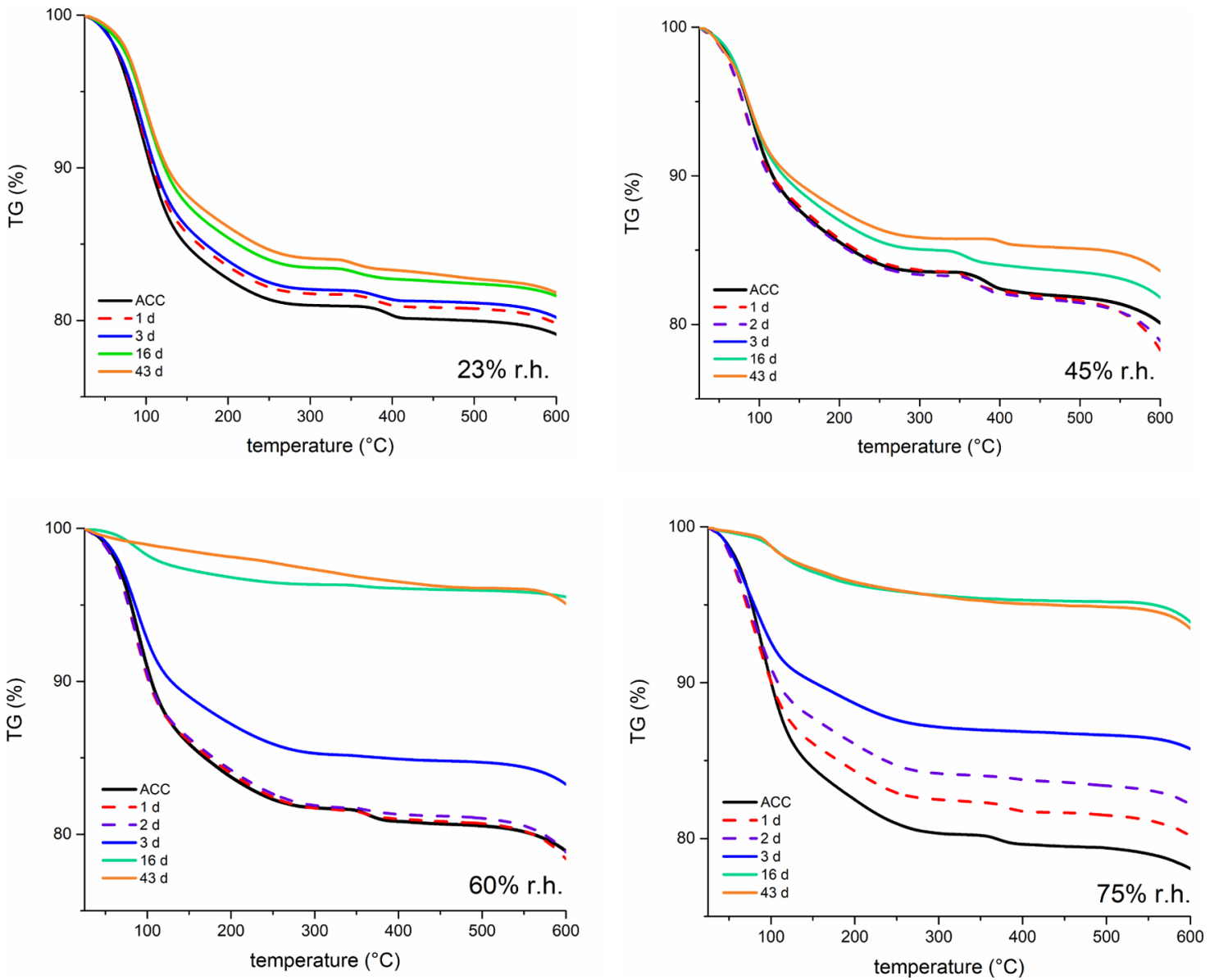

Figure 5. TGA curves of the ACC samples exposed to $23,45,60$, and $75 \%$ of relative humidity at different sampling times. 

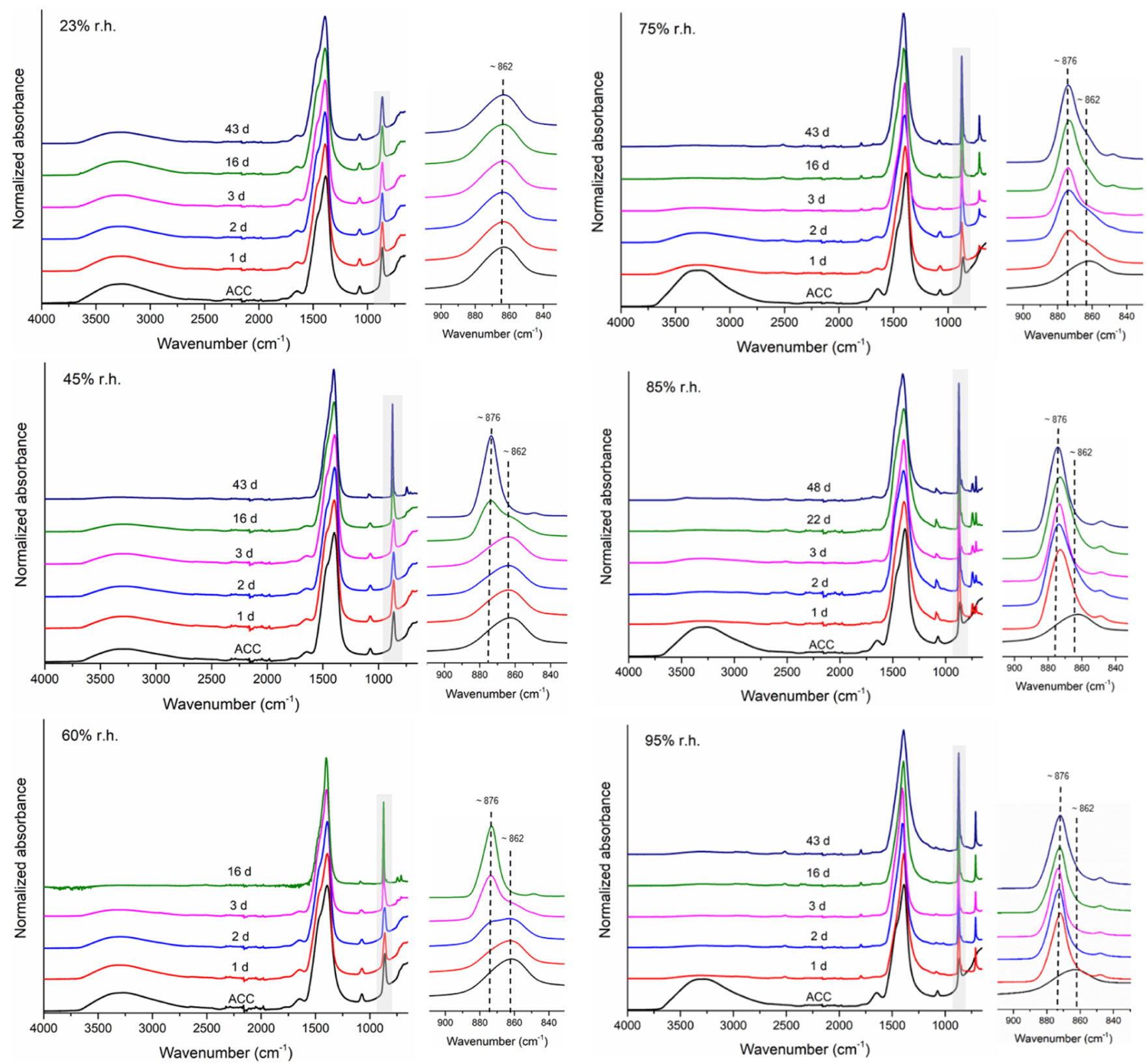

Figure 6. ATR-FTIR absorption spectra of ACC at different relative humidities at different sampling times. Similar to the results obtained at $23 \%$ $\mathrm{RH}$, at $33 \% \mathrm{RH}$, no changes were observed during 43 days of the experiment (data not shown).

amorphous solids. ${ }^{26}$ The $q$-range used during these experiments gives access to the nanoscale dynamics $(d \sim 50 \mathrm{~nm})$. Whereas no changes are observed in the static structure factor at this length scale (Figure S5), it is possible that some minor structural changes concomitant to the partial dehydration process are present at the atomic scale. Indeed, previous studies have shown that very minor structural changes can result in large modifications of the dynamic behavior. ${ }^{27}$

The evolution of the relaxation time $\tau$ and shape factor $\beta$ during the course of the XPCS experiments (sample aging) gives some hints about the stability of the different thermally treated samples. Relaxation times for the as-synthesized sample reach a plateau and show an evolution similar to that of the ACC- $250{ }^{\circ} \mathrm{C}$ sample, except for the initial shift in the initial relaxation time, $\tau_{0}$. This is in contrast with the behavior observed for the ACC- $140{ }^{\circ} \mathrm{C}$ sample, which shows a steeper increase of the relaxation time. We ascribe this difference in behavior to a potential difference in stability of the different samples. Three different types of water can be identified in ACC samples from a purely operational (TGA) definition: (i) adsorbed, mobile water ( $\left.\mathrm{RT}-150{ }^{\circ} \mathrm{C}\right)$; (ii) structural, rigid water $\left(150{ }^{\circ} \mathrm{C}-250{ }^{\circ} \mathrm{C}\right)$; and (iii) trapped water (water released during crystallization at about $342{ }^{\circ} \mathrm{C}$, including hydroxyl). ${ }^{19,26,41}$ A previous work reported the possible redistribution of water between the different hydrous components in ACC. ${ }^{19}$ We hypothesize that the removal of the adsorbed water component from ACC- $140{ }^{\circ} \mathrm{C}$ could result in a continuous redistribution of water within the sample, which could affect its stability. The continuous and steep slowing down of the dynamics could be interpreted in that case as a dehydration step preceding crystallization. Under the same hypothesis, the similar aging behavior of the other two samples (ACC and ACC-250 ${ }^{\circ} \mathrm{C}$ ) could thus be due to higher stability of these samples, with all hydrous compartments being filled in 

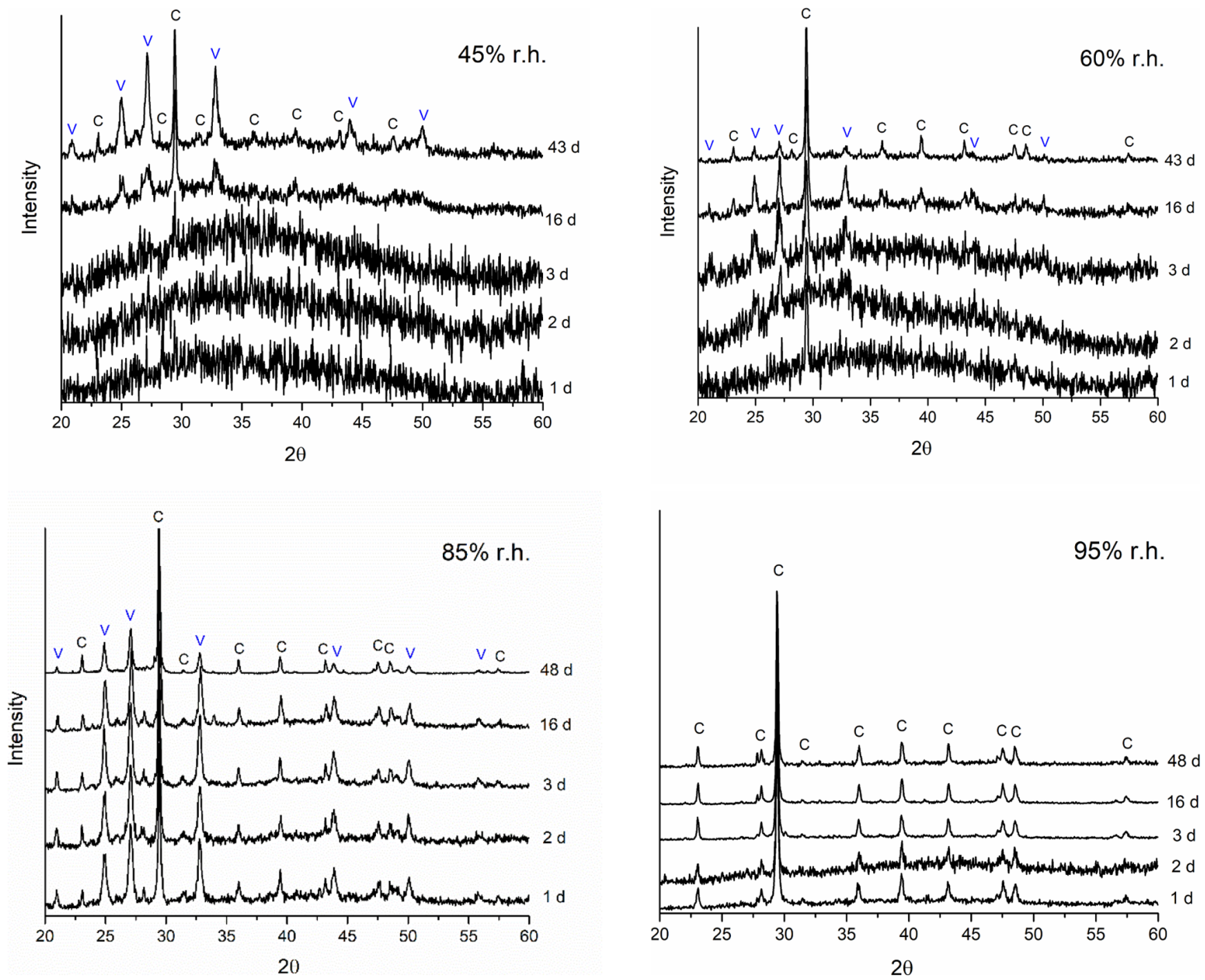

Figure 7. XRD patterns obtained with a $\mathrm{Cu} \mathrm{K} \alpha$ source (wavelength $=1.54 \AA$ ) at different experimental times for ACC exposed to $45,60,85$, and $95 \% \mathrm{RH}$.

the ACC sample and only the less mobile residual trapped water in ACC-250 ${ }^{\circ} \mathrm{C} .{ }^{19}$

Rehydration of the samples after exposure to humidity results in regain of adsorbed mobile water (Figure 3). The concomitant reactivation of the dynamics observed by XPCS shows that this water is associated with at least some of the dynamic modes of ACC. The steep slowing down of the dynamics observed for the sample ACC-250 ${ }^{\circ} \mathrm{C}$ could be associated with destabilization (Figure 4e). We hypothesize that the observed slowing down of the dynamics after rehydration of this sample is associated with minor structural changes related to the beginning of the crystallization process (Figure 9). XPCS data at higher $q$ (atomic scale) would be needed to test this hypothesis. An interesting observation comes from the fact that no change in the dynamics was observed after exposure to $35 \% \mathrm{RH}$ for $20 \mathrm{~min}$. This result could suggest the existence of a threshold value of humidity below which the amount of adsorbed water is not enough to reactivate the internal dynamics. However, the relatively short time of exposure $(20 \mathrm{~min}$, against $270 \mathrm{~min}$ for the sample exposed to $57 \% \mathrm{RH}$ ) could also imply that the lack of effect is related to a slow rehydration process.
Crystallization Kinetics Controlled by Ion Dynamics. Different scenarios are discussed that provide different explanations of the results of ACC crystallization experiments under controlled RH.

Dissolution-Precipitation Scenario. This scenario assumes that calcium and carbonate from ACC dissolve in a bulk-like solution inside the highly hydrated-solid material and that a bulk aqueous solution compartment is present around the growing calcite crystals. Calcite crystal sizes formed from ACC during our experiments are directly proportional to the value of the RH (Figure 9). If the ACC crystallization mechanism is a dissolution-precipitation process, then the thermodynamic driving force for the formation of calcite after ACC dissolution is the higher solubility of ACC relative to that of calcite. Different hypotheses can be made to explain the fact that the final calcite crystals have different sizes as a function of the water content:

Solubility of ACC Changes as a Function of the Water Content. This is a plausible hypothesis, and results from calorimetry experiments have shown that enthalpies of formation of ACC actually depend on its water content. ${ }^{42}$ According to classical nucleation theory, the nucleation rate $J_{n}$ 

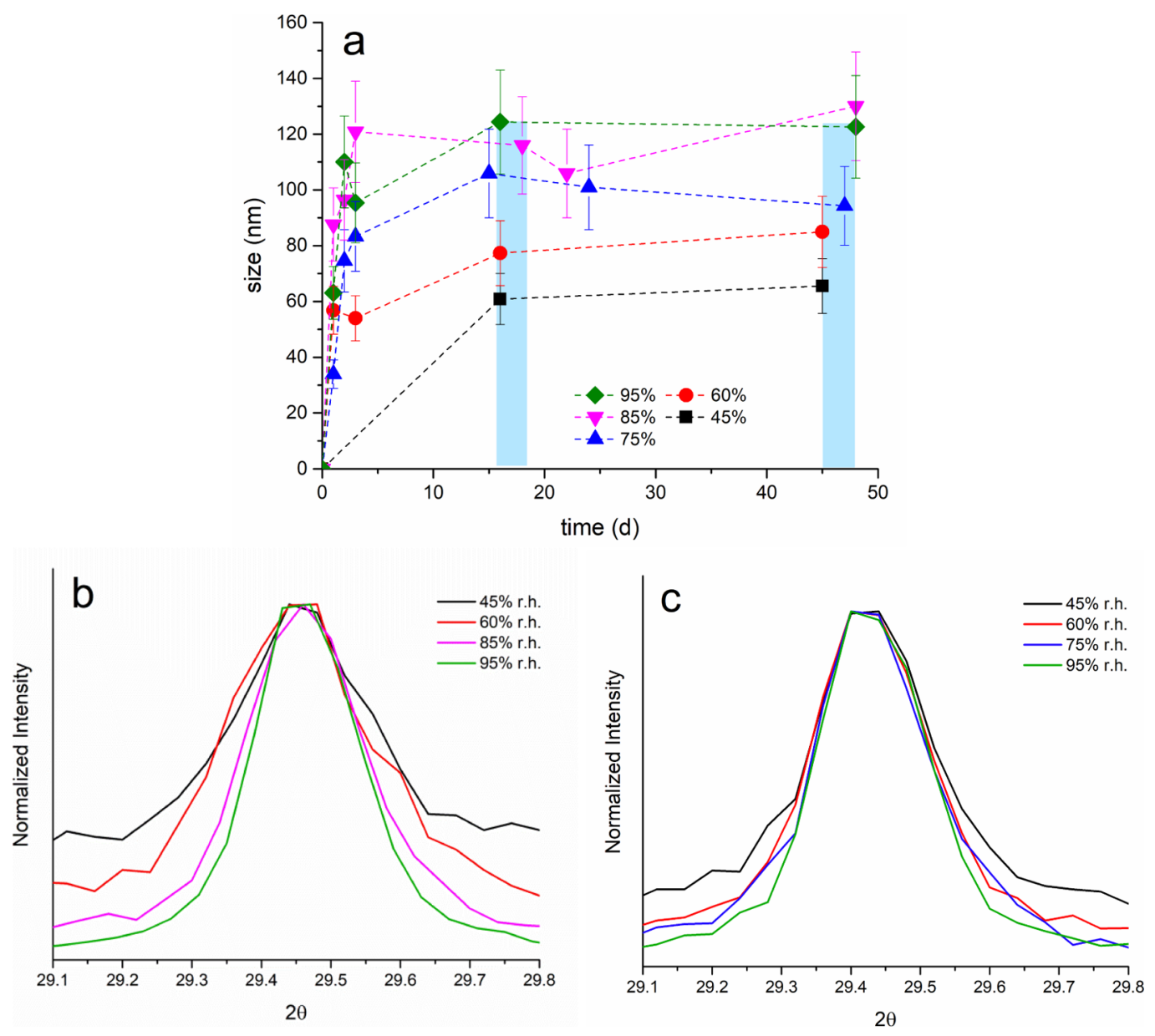

Figure 8. (a) Calcite crystal size evolution during the first 48 days of crystallization at different RHs, (b) diffraction calcite peaks at $29.45^{\circ}$ after 16-18 days ( 16 days for the 45,60 , and $95 \%$ RH experiments and 18 days for $85 \% \mathrm{RH}$ ), and (c) after $43-48$ days ( 43 days for 45 and $60 \% \mathrm{RH}, 48$ days for 75 , and $95 \% \mathrm{RH})$. (b,c) correspond to the points inside the shadowed areas of figure (a).

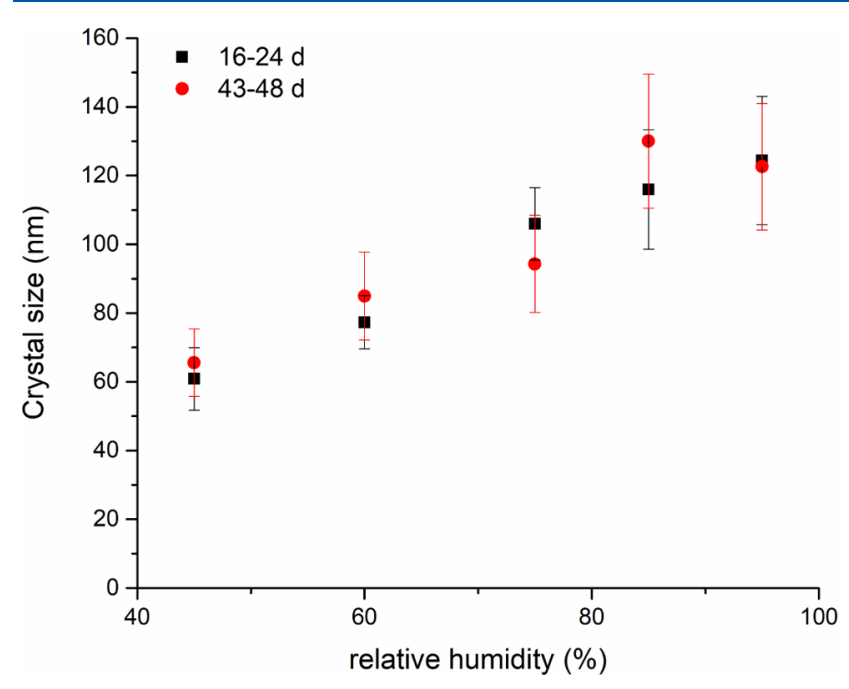

Figure 9. Calcite domain size as a function of relative humidity after $16-24$ and $43-48$ days, when the maximum crystal size is reached and all ACC is transformed to calcite.

(number of crystalline nuclei formed per unit of time) increases with the solution supersaturation with a proportionality relationship $J_{\mathrm{n}} \propto \mathrm{e}^{-1 / \sigma^{2}}$, that is, a higher solution supersaturation (i.e., low $\mathrm{RH}$ ) would result in large amounts of nuclei formed per unit of time. ${ }^{43}$ If more hydrated ACC (higher RH) is more soluble, as reported by Radha et al., ${ }^{42}$ then the solution would be more supersaturated, resulting in the nucleation of smaller crystals, a trend reversed with respect to our observations.

ACC Crystal Size is Controlled by Diffusion Barriers at the Crystal-Water Interfaces. The high water content in ACC and its higher solubility with respect to calcite make the hypothesis plausible that ACC dissolution does not impose a kinetic limiting step to the crystallization kinetics. ${ }^{44}$ We can therefore assume that the solution is in equilibrium with ACC, implying a constant solution supersaturation with respect to calcite. Growth of the crystalline nuclei under these conditions would not be exempt of kinetic barriers related to transport of ions through the aqueous solution surrounding the calcite crystals. We have considered this scenario by performing finiteelement simulations of ion transport across boundary water layers at the crystal-water interfaces, coupled to solution chemistry calculations of saturation indexes (SI), and implementing calcite precipitation reactions using Comsol Multiphysics solver. ${ }^{45}$ COMSOL was used to simulate ACC dissolution and the evolution of concentration gradients during calcite growth. In the model, a spherical calcite seed of $0.02 \mathrm{~nm}$ radius was placed in the center of a $2 \mathrm{~nm}$ radius circular section domain, which corresponds to 6-7 physisorbed water molecules. Calcite precipitation was modeled with a reaction 
growth rate, $J=k(\sigma-1)$, where $\mathrm{J}$ is the growth rate, $\sigma$ is the SI with respect to calcite, and $k$ is the rate constant. A value of $k=$ $10^{-11.19} \mathrm{~mol} / \mathrm{cm}^{2} \cdot \mathrm{s}$ was used. ${ }^{46}$ The simulation was performed in the presence of ACC, which dissolves providing a constant ion concentration that remains constant and equal to the solubility of ACC at $25{ }^{\circ} \mathrm{C}$ proposed by Brečevic and Nielsen. ${ }^{47}$ Different values of the diffusion coefficients were tested: $1 \cdot 10^{-9} \mathrm{~m}^{2} / \mathrm{s}$, which falls within the typical range of diffusion coefficient of ions, ${ }^{48}$ and a slower value of $1 \cdot 10^{-15}$ $\mathrm{m}^{2} / \mathrm{s}$ for comparison. The results of the simulations show that even if a very slow self-diffusion coefficient is considered for the diffusion of $\mathrm{Ca}^{2+}\left(1 \cdot 10^{-15} \mathrm{~m}^{2} / \mathrm{s}\right)$, concentration gradients are absent after $0.1 \mathrm{~s}$ of simulation. The modeled amount of calcite precipitated in the spherical reservoir after $0.1 \mathrm{~s}$ reached the total amount of calcite precipitated during our experiments over 15-18 days. These results suggest that ion diffusion through boundary layers is not the mechanism limiting the transformation of ACC into calcite (see Supporting Information, section Geochemical Modeling, Figure S6).

The lack of agreement of our results with the dissolutionprecipitation scenario agrees with past reports showing that the transformation of ACC into crystalline $\mathrm{CaCO}_{3}$ is triggered after the physisorption of a critical $\mathrm{H}_{2} \mathrm{O}$ level. ${ }^{13}$ Konrad et al. ${ }^{13}$ described the formation of a thin layer of adsorbed water of $\sim 1.2 \mathrm{~nm}$ as the threshold value above which the $90 \mathrm{~nm}$ ACC particles of their experiments would transform into crystalline polymorphs via a dissolution-precipitation mechanism. Below this level, ACC remained in its metastable state, and above it, due to the high ACC solubility, the adsorbed water on the ACC surface induced its dissolution forming a highly supersaturated surface solution with respect to the metastable intermediate phases (anhydrous calcium carbonate crystalline forms). ${ }^{11,13,49}$ The evolution of the crystal size as a function of the $\mathrm{RH}$ reported in Figure 9 could indicate a stabilization (plateau) of the crystal size at high $\mathrm{RH}$ that would be in agreement with the scenario by which the crystal size is independent of the water content (i.e., the solution is in equilibrium with ACC providing a constant supersaturation and therefore a constant crystal size irrespective of water content). This would agree as well with the proposition of a threshold value of activation of the dissolution-precipitation mechanisms that would be placed in this case at $\sim 80 \% \mathrm{RH}$ The evolution of the crystal size for $\mathrm{RH}$ values below this threshold needs then further explanation.

Structural Reorganization and Crystallization Mediated by Structural Water with Reduced Activity. Adsorbed water forms thin films on the surfaces and "pockets" within the pores of ACC, eventually forming bulk-like water environments at high $\mathrm{RH}$ values. It is well known that the structuring of adsorbed and structural water results in modified thermodynamic properties with respect to those of the bulk phase. ${ }^{50}$ This scenario assumes that supersaturation conditions within the hydrated ACC structure can be modeled using solution chemistry concepts by lowering the activity coefficient of water $\left(a_{\mathrm{w}}<1\right)$. The decrease in RH (i.e., water activity, see theory and equations section and speciation-solubility calculations in the Supporting Information) causes an increase of the solution supersaturation with a subsequent increase of the nucleation rate $\left(\alpha-1 / \sigma^{2}\right.$, where $\sigma$ is the SI) and a decrease of the critical radius for nucleation $(\propto 1 / \sigma)$ which is consistent with the smaller crystal sizes of calcite found at lower values of the $\mathrm{RH}$ (Figures 8 and 9). Relative changes in the values of the calculated size of the critical nucleus are used here to interpret the experimental results. The calculated critical radius from the saturation indices at different RHs shows small changes in size (3\%) between 85 and 95\% RH (Figure S7), which would be consistent with the similar calcite crystal size observed in the experiments at these two RHs (Figure 9). The decrease of the calculated size of the critical radius from $95 \% \mathrm{RH}$ to $45 \% \mathrm{RH}$ which is about $15 \%$ (Figure S7) is to be compared with a decrease of $50 \%$ of the calcite size found in the experiments (Figures $8 \mathrm{a}$ and 9). These values, though not perfectly aligned, fall within the same order of magnitude. We hypothesize that differences could be due to the slow diffusivity of ions within the ACC material which, unlike in aqueous solutions, would result in a limited supply of ions for the growing nuclei. This "confinement" effect within the amorphous matrix could therefore be affecting the growth of the crystalline nuclei, limiting their size. On the other hand, the higher ionic diffusivity in more hydrated ACC found by XPCS (Figure 4) could result in larger ionic diffusion lengths within the amorphous structure, which would then result in larger crystals, as found experimentally.

Another factor that could be responsible for the discrepancy is that the value of the water activity used in the calculations was imposed from the one corresponding to the partial pressure of water in the humidity chamber. The partitioning of water among all the surfaces and pores of ACC probably results in environments having highly contrasting values of water activity that could be as well influencing the crystallization kinetics.

This approach shows thus a partial agreement with the experimental results. The amount of water present within the ACC at low $\mathrm{RH}$ is enough to spark structural reorganizations within the material that are enough to drive the formation of crystalline nuclei of critical size. This "crystallization of ACC by solid-state transformation" is interpreted here using a reduced activity for the water component. Past investigations of water mobility within ACC have shown deviations with respect to the behavior of bulk water, justifying this approach. ${ }^{23,26}$ In this sense, the solid-state transformation is understood as a structural reorganization mediated by the presence of water.

Our XPCS results support the idea of an activation of the dynamics by water. As mentioned above, this activation could result in longer diffusion lengths that would enhance crystal growth. However, the higher diffusivity also affects the nucleation rate. As shown by Koishi et al., ${ }^{26}$ a value for the number of structural re-arrangements within the material per unit of time can be derived from the relaxation times, $\omega=1 / \tau$. This frequency, $\omega$, is directly proportional to the nucleation rate (see details in the X-ray photon correlation spectroscopy section of the Supporting Information). ${ }^{26}$ The increase in the value of this kinetic pre-factor should therefore accelerate the nucleation rate, resulting potentially in a larger number of smaller crystals. The opposite trend shown in the experimental results (larger crystals under higher humidity) imply that other factors such as those mentioned above (confinement and water partitioning) dominate the crystallization kinetics.

\section{CONCLUSIONS}

The results of the XPCS experiments presented here show different aspects of the dynamical behavior of ACC. Water content in ACC is directly correlated with the diffusion dynamics, showing a reversible behavior that suggests the existence of a threshold value of the concentration of adsorbed 
water needed to reactivate the diffusional dynamics. The nature of the diffusion is close to Brownian for samples with a higher degree of hydration (fresh ACC). However, the desorption of a small amount of physisorbed water induces an increase in the shape factor $\beta$, revealing a different nature of the dynamic behavior, far from ideal Brownian dynamics. A link between these results is made with the crystallization kinetics through the frequency of structural rearrangement, which is one of the parameters in the kinetic prefactor of classical nucleation theory. If the XPCS results are taken alone, this kinetic factor should increase proportionally to the water concentration within the samples, which would lead to a larger amount of smaller crystals at the end of the crystallization experiments. However, the opposite trend observed suggests that other factors such as the confinement of the calcite crystals within the amorphous matrix could be the reason for the larger size of the crystals observed at higher humidity.

Future studies will be devoted to studying the structural and dynamical characteristics of the different types of water present in the ACC samples (adsorbed vs bulk) and the impact of the $\mathrm{RH}$ on this partitioning.

\section{ASSOCIATED CONTENT}

\section{SI Supporting Information}

The Supporting Information is available free of charge at https://pubs.acs.org/doi/10.1021/acs.jpcc.0c08670.

Methods; two-time correlation function of the sample ACC- $250{ }^{\circ} \mathrm{C}$; ATR-FTIR spectra of ACC and calcite; XRD of ACC and calcite; TGA-DSC of ACC and calcite; representative time-evolution of the intensity profile for ACC; COMSOL model of the diffusion of Ca versus distance and of calcite precipitated over time; calculated calcite SI and critical radius at different $\mathrm{RH}$; fit parameters obtained from the intensity autocorrelation functions for ACC thermally untreated and treated samples; samples exposed to different levels of relative humidity measured by XPCS; and water content and crystallinity of synthesized ACC over time under different relative humidity conditions (PDF)

\section{AUTHOR INFORMATION}

\section{Corresponding Author}

Maria P. Asta - Universite Grenoble Alpes, Université Savoie Mont Blanc, CNRS, IRD, IFSTTAR, ISTerre, 38000 Grenoble,

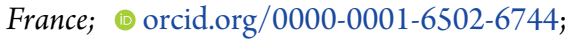

Email: mariapilar.astaandres@unil.ch

\section{Authors}

Alejandro Fernandez-Martinez - Université Grenoble Alpes, Université Savoie Mont Blanc, CNRS, IRD, IFSTTAR, ISTerre, 38000 Grenoble, France; (1) orcid.org/0000-0001-5073-9629

Juan Alonso - Geoenvironmental Engineering Group, University of Castilla La-Mancha, 45007 Toledo, Spain

Laurent Charlet - Université Grenoble Alpes, Université Savoie Mont Blanc, CNRS, IRD, IFSTTAR, ISTerre, 38000 Grenoble, France; (1) orcid.org/0000-0003-3669-7316

Nathaniel Findling - Université Grenoble Alpes, Université Savoie Mont Blanc, CNRS, IRD, IFSTTAR, ISTerre, 38000 Grenoble, France

Valerie Magnin - Université Grenoble Alpes, Université Savoie Mont Blanc, CNRS, IRD, IFSTTAR, ISTerre, 38000 Grenoble, France
Beatrice Ruta - Université Lyon, Université Claude Bernard Lyon 1, CNRS, Institut Lumiere Matiere, 69622 Villeurbanne, France

Michael Sprung - Deutsches Elektronen Synchrotron DESY, D22607 Hamburg, Germany

Fabian Westermeier - Deutsches Elektronen Synchrotron DESY, D-22607 Hamburg, Germany

Complete contact information is available at:

https://pubs.acs.org/10.1021/acs.jpcc.0c08670

\section{Author Contributions}

The manuscript was written with contributions of all authors. All authors have approved the final version of the manuscript.

Notes

The authors declare no competing financial interest.

\section{ACKNOWLEDGMENTS}

This project has received funding from the European Union's Horizon 2020 research and innovation programme under the Marie Skłodowska-Curie grant agreement 747597. The authors acknowledge funding by the French National Research Agency (ANR-JCJC “NUANCE”, grant ANR-17-CE08-0057). We thank Dr. Gaston Garbarino (ESRF) for his help preparing the steel gaskets for the XPCS measurements and Dr. Cristina Palencia and Dr. Kathrin Hoppe (Institut of Physical Chemistry, Univ. Hamburg, Germany) for their assistance with TGA experiments. Use of the analytical chemistry platform of ISTerre (France) is acknowledged.

\section{REFERENCES}

(1) Addadi, L.; Raz, S.; Weiner, S. Taking Advantage of Disorder: Amorphous Calcium Carbonate and Its Roles in Biomineralization. Adv. Mater. 2003, 15, 959-970.

(2) DeVol, R. T.; Sun, C.-Y.; Marcus, M. A.; Coppersmith, S. N.; Myneni, S. C. B.; Gilbert, P. U. P. A. Nanoscale Transforming Mineral Phases in Fresh Nacre. J. Am. Chem. Soc. 2015, 137, 13325-13333.

(3) Politi, Y.; Arad, T.; Klein, E.; Weiner, S.; Addadi, L. Sea Urchin Spine Calcite Forms via a Transient Amorphous Calcium Carbonate Phase. Science 2004, 306, 1161-1164.

(4) Yang, L.; Killian, C. E.; Kunz, M.; Tamura, N.; Gilbert, P. U. P. A. Biomineral Nanoparticles Are Space-Filling. Nanoscale 2011, 3, 603-609.

(5) Cölfen, H. Crystal-Clear View. Nat. Mater. 2010, 9, 960-961.

(6) De Yoreo, J. J.; Gilbert, P. U. P. A.; Sommerdijk, N. A. J. M.; Penn, R. L.; Whitelam, S.; Joester, D.; Zhang, H.; Rimer, J. D.; Navrotsky, A.; Banfield, J. F.; et al. Crystallization by Particle Attachment in Synthetic, Biogenic, and Geologic Environments. Science 2015, 349, aaa6760.

(7) Beniash, E.; Aizenberg, J.; Addadi, L.; Weiner, S. Amorphous Calcium Carbonate Transforms into Calcite during Sea Urchin Larval Spicule Growth. Proc. R. Soc. B 1997, 264, 461-465.

(8) Xiang, L.; Kong, W.; Su, J.; Liang, J.; Zhang, G.; Xie, L.; Zhang, R. Amorphous Calcium Carbonate Precipitation by Cellular Biomineralization in Mantle Cell Cultures of Pinctada Fucata. PLoS One 2014, 9, No. e113150.

(9) Blondeau, M.; Sachse, M.; Boulogne, C.; Gillet, C. Amorphous Calcium Carbonate Granules Form Within an Intracellular Amorphous Calcium Carbonate Granules Form Within an Intracellular Compartment in Calcifying Cyanobacteria. Front. Microbiol. 2018, 9, 1-14.

(10) Gower, L. B. Biomimetic Model Systems for Investigating the Amorphous Precursor Pathway and Its Role in Biomineralization. Chem. Rev. 2008, 108, 4551-4627. 
(11) Xu, X.; Han, J. T.; Kim, D. H.; Cho, K. Two Modes of Transformation of Amorphous Calcium Carbonate Films in Air. J. Phys. Chem. B 2006, 110, 2764-2770.

(12) Ihli, J.; Wong, W. C.; Noel, E. H.; Kim, Y. Y.; Kulak, A. N.; Christenson, H. K.; Duer, M. J.; Meldrum, F. C. Dehydration and Crystallization of Amorphous Calcium Carbonate in Solution and in Air. Nat. Commun. 2014, 5, 3169.

(13) Konrad, F.; Gallien, F.; Gerard, D. E.; Dietzel, M. Transformation of Amorphous Calcium Carbonate in Air. Cryst. Growth Des. 2016, 16, 6310-6317.

(14) Nielsen, M. H.; Aloni, S.; De Yoreo, J. J. In Situ TEM Imaging of CaCO3 Nucleation Reveals Coexistence of Direct and Indirect Pathways. Science 2014, 345, 1158-1162.

(15) Rodriguez-Blanco, J. D.; Shaw, S.; Benning, L. G. The Kinetics and Mechanisms of Amorphous Calcium Carbonate (ACC) Crystallization to Calcite, via Vaterite. Nanoscale 2011, 3, 265-271.

(16) Fernandez-Martinez, A.; Kalkan, B.; Clark, S. M.; Waychunas, G. A. Pressure-Induced Polyamorphism and Formation of "aragonitic" Amorphous Calcium Carbonate. Angew. Chem. Int. Ed. 2013, 52, 8354-8357.

(17) Nishiyama, Y.; Asaadi, S.; Ahvenainen, P.; Sixta, H. WaterInduced Crystallization and Nano-Scale Spinodal Decomposition of Cellulose in NMMO and Ionic Liquid Dope. Cellulose 2019, 26, 281289.

(18) Miyazaki, T.; Kaneko, T.; Gong, J. P.; Osada, Y.; Demura, M.; Suzuki, M. Water-Induced Crystallization of Hydrogels. Langmuir 2002, 18, 965-967.

(19) Schmidt, M. P.; Ilott, A. J.; Phillips, B. L.; Reeder, R. J. Structural Changes upon Dehydration of Amorphous Calcium Carbonate. Cryst. Growth Des. 2014, 14, 938-951.

(20) Cobourne, G.; Mountjoy, G.; Rodriguez-Blanco, J. D.; Benning, L. G.; Hannon, A. C.; Plaisier, J. R. Neutron and X-Ray Diffraction and Empirical Potential Structure Refinement Modelling of Magnesium Stabilised Amorphous Calcium Carbonate. J. Non-Cryst. Solids 2014, 401, 154-158.

(21) Michel, F. M.; MacDonald, J.; Feng, J.; Phillips, B. L.; Ehm, L.; Tarabrella, C.; Parise, J. B.; Reeder, R. J. Structural Characteristics of Synthetic Amorphous Calcium Carbonate. Chem. Mater. 2008, 20, $4720-4728$.

(22) Wang, H.-W.; Daemen, L. L.; Cheshire, M. C.; Kidder, M. K.; Stack, A. G.; Allard, L. F.; Neuefeind, J.; Olds, D.; Liu, J.; Page, K. Synthesis and Structure of Synthetically Pure and Deuterated Amorphous (Basic) Calcium Carbonates. Chem. Commun. 2017, 53, 2942-2945.

(23) Jensen, A. C. S.; Rodriguez, I.; Habraken, W. J. E. M.; Fratzl, P.; Bertinetti, L. Mobility of Hydrous Species in Amorphous Calcium/ Magnesium Carbonates. Phys. Chem. Chem. Phys. 2018, 20, 1968219688.

(24) Fernandez-Martinez, A.; Lopez-Martinez, H.; Wang, D. Structural Characteristics and the Occurrence of Polyamorphism in Amorphous Calcium Carbonate. New Perspectives on Mineral Nucleation and Growth; Springer International Publishing: Cham, 2017; pp 77-92.

(25) Albéric, M.; Bertinetti, L.; Zou, Z.; Fratzl, P.; Habraken, W.; Politi, Y. The Crystallization of Amorphous Calcium Carbonate Is Kinetically Governed by Ion Impurities and Water. Adv. Sci. 2018, 5, 1701000 .

(26) Koishi, A.; Fernandez-Martinez, A.; Ruta, B.; Jimenez-Ruiz, M.; Poloni, R.; Di Tommaso, D.; Zontone, F.; Waychunas, G. A.; MontesHernandez, G. Role of Impurities in the Kinetic Persistence of Amorphous Calcium Carbonate: A Nanoscopic Dynamics View. J. Phys. Chem. C 2018, 122, 16983-16991.

(27) Giordano, V. M.; Ruta, B. Unveiling the Structural Arrangements Responsible for the Atomic Dynamics in Metallic Glasses during Physical Aging. Nat. Commun. 2016, 7, 10344.

(28) Ruta, B.; Baldi, G.; Chushkin, Y.; Rufflé, B.; Cristofolini, L.; Fontana, A.; Zanatta, M.; Nazzani, F. Revealing the Fast Atomic Motion of Network Glasses. Nat. Commun. 2014, 5, 3939.
(29) Kashchiev, D. Nucleation: Basic Theory with Applications; Butterworth Heinemann: Oxford, 2000.

(30) Jensen, A. C. S.; Imberti, S.; Habraken, W. J. E. M.; Bertinetti, L. Small Ionic Radius Limits Magnesium Water Interaction in Amorphous Calcium/Magnesium Carbonates. J. Phys. Chem. C 2020, 124, 6141-6144.

(31) Radha, A. V.; Fernandez-Martinez, A.; Hu, Y.; Jun, Y.-S.; Waychunas, G. A.; Navrotsky, A. Energetic and Structural Studies of Amorphous Ca1-XMgxCO3.nH2O $(0 \leq \mathrm{x} \leq 1)$. Geochim. Cosmochim. Acta 2012, 90, 83-95.

(32) Madsen, A.; Fluerasu, A.; Ruta, B. Structural Dynamics of Materials Probed by X-Ray Photon Correlation Spectroscopy. In Synchrotron Light Sources and Free-Electron Lasers: Accelerator Physics, Instrumentation and Science Applications; Jaeschke, E. J., Khan, S., Schneider, J. R., Hastings, J. B., Eds.; Springer International Publishing: Cham, 2016; pp 1617-1641.

(33) Young, J. F. Humidity Control in the Laboratory Using Salt Solutions-a Review. J. Appl. Chem. 1967, 17, 241-245.

(34) Carr, D. S.; Harris, B. L. Solutions for Maintaining Constant Relative Humidity. Ind. Eng. Chem. 1949, 41, 2014-2015.

(35) Richardson, G. M.; Malthus, R. S. Salts for Static Control of Humidity at Relatively Low Levels. J. Appl. Chem. 1955, 5, 557-567.

(36) Müller, L.; Waldorf, M.; Gutt, C.; Grubel, G.; Madsen, A.; Finlayson, T. R.; Klemradt, U. Slow Aging Dynamics and Avalanches in a Gold-Cadmium Alloy Investigated by X-Ray Photon Correlation Spectroscopy. Phys. Rev. Lett. 2011, 107, 105701.

(37) Stephens, C. J.; Ladden, S. F.; Meldrum, F. C.; Christenson, H. K. Amorphous Calcium Carbonate Is Stabilized in Confinement. Adv. Funct. Mater. 2010, 20, 2108-2115.

(38) Scherrer, P. Bestimmung Der Grosse Und Der Inneren Struktur von Kolloidteilchen Mittels Rontgenstrahlen, Nachrichten von Der Gesellschaft Der Wissenschaften, Gottingen. Math.-Phys. Kl. 1918, 2, 98-100.

(39) Ferrero, E. E.; Martens, K.; Barrat, J. L. Relaxation in Yield Stress Systems through Elastically Interacting Activated Events. Phys. Rev. Lett. 2014, 113, 248301.

(40) Bouzid, M.; Colombo, J.; Barbosa, L. V.; Del Gado, E. Elastically Driven Intermittent Microscopic Dynamics in Soft Solids. Nat. Commun. 2017, 8, 15846.

(41) Tribello, G. A.; Bruneval, F.; Liew, C.; Parrinello, M. A Molecular Dynamics Study of the Early Stages of Calcium Carbonate Growth. J. Phys. Chem. B 2009, 113, 11680-11687.

(42) Radha, A. V.; Forbes, T. Z.; Killian, C. E.; Gilbert, P. U. P. A.; Navrotsky, A. Transformation and Crystallization Energetics of Synthetic and Biogenic Amorphous Calcium Carbonate. Proc. Natl. Acad. Sci. U.S.A. 2010, 107, 16438-16443.

(43) De Yoreo, J. J.; Vekilov, P. G. Principles of Crystal Nucleation and Growth. Rev. Mineral. Geochem. 2003, 54, 57-94.

(44) Kellermeier, M.; Picker, A.; Kempter, A.; Cölfen, H.; Gebauer, D. A Straightforward Treatment of Activity in Aqueous $\mathrm{CaCO} 3$ Solutions and the Consequences for Nucleation Theory. Adv. Mater. 2014, 26, 752-757.

(45) COMSOL Multiphysics Reference Manual, version 5.1, 2015.

(46) Reddy, M. M.; Nancollas, G. H. The Crystallization of Calcium Carbonate I. J. Colloid Interface Sci. 1971, 36, 166-172.

(47) Brečević, L.; Nielsen, A. E. Solubility of Amorphous Calcium Carbonate. J. Cryst. Growth 1989, 98, 504-510.

(48) Lerman, A. Geochemical Processes. Water and Sediment Environments; John Wiley \& Sons: New York, 1979.

(49) Putnis, A. Why Mineral Interfaces Matter. Science 2014, 343, $1441-1442$.

(50) Tang, M.; Cziczo, D. J.; Grassian, V. H. Interactions of Water with Mineral Dust Aerosol: Water Adsorption, Hygroscopicity, Cloud Condensation, and Ice Nucleation. Chem. Rev. 2016, 116, 42054259. 